\title{
The Reaction of Chlorotetrafluorophosphorane with Trimethylamine
}

\author{
R M KREN
}

Department of Chemistry, University of Michigan-Flint, Flint, Mich 48503, US A

A H COWLEY* and M V SMALLFY

Department of Chemistry, The University of Texas at Austın, Austın, Tex 78712, US A

Reccived May 22, 1980

The reaction of chlorotetrafluorophosphorane with trimethylamine affords a 1 Lewis actd-base complex of composition $\mathrm{ClF}_{4} \mathrm{P} \cdot \mathrm{NMe}_{3}$ It has been established by ${ }^{1} \mathrm{H}$ and ${ }^{19} \mathrm{~F} N M R$ spectroscopy that the $\mathrm{Cl}$ and $\mathrm{Me}_{3} \mathrm{~N}$ ligands occupy mutually trans positions in a locally octahedral geometry around phosphorus

\section{Introduction}

One of the most useful and well recognized properties of the pentahalides of Group VA relates to their acceptor behavior However, whlle numerous com. plexes of the type Base $\rightarrow \mathrm{MX}_{5}(\mathrm{M}=\mathrm{P}, \mathrm{As}, \mathrm{Sb}, \mathrm{X}=$ halogen) have been characterized $[1,2]$, we are not aware of the synthesis of any complexes featuring mixed halophosphoranes of the type Base $\rightarrow \mathrm{MF}_{4} \mathrm{X}$ $(X \neq F)$ Such complexes are of interest because of the possibility of geometrical isomerism The present study concerns the reactions of $\mathrm{PF}_{4} \mathrm{Cl}$ with $\mathrm{Me}_{3} \mathrm{~N}$

\section{Experimental}

\section{Preparations}

Due to the moisture and/or oxygen sensitivity of boron and phosphorus halides it was necessary to perform all operations in an inert atmosphere or in a Pyrex vacuum system of standard design Boron trlchloride and $\mathrm{PF}_{5}$ were procured commercially and used without subsequent purification Chlorotetrafluorophosphorane was prepared by the vapor-phase reaction of $\mathrm{PF}_{5}$ with $\mathrm{BCl}_{3}$ [3], and purified by trapto-trap distillation until the infrared spectrum conformed to the one reported in the literature [4]

In a typical preparation of $\mathrm{ClF}_{4} \mathrm{P} \cdot \mathrm{NMe}_{3}, 55 \mathrm{mmol}$ of $\mathrm{PF}_{4} \mathrm{Cl}$ and $100 \mathrm{mmol}$ of $\mathrm{Me}_{3} \mathrm{~N}$ were condensed into the side-arm of an evacuated $2-\mathrm{L}$ reaction bulb at $-196{ }^{\circ} \mathrm{C}$ and allowed to warm slowly to room temperature Formation of a white solid was apparent as soon as the reaction mixture melted Excess of $\mathrm{Me}_{3} \mathrm{~N}$ (beyond that required for formation of the $11 \mathrm{com}$ -

\footnotetext{
*Author to whom correspondence should be addressed
}

plex) was removed quantitatively from the reaction mixture after allowing it to stand for 30 minutes at room temperature The white solid product, which fumes in moist alr, partially sublimes at $\sim 80{ }^{\circ} \mathrm{C}$ in a sealed melting point capillary, leaving a residual infusible $\left(<300^{\circ} \mathrm{C}\right)$ brown mass With rapid heating, samples darken at $\sim 80^{\circ} \mathrm{C}$ and decompose rapidly at $\sim 90{ }^{\circ} \mathrm{C}$, with evidence of sublimation Anal Calcd for $\mathrm{C}_{3} \mathrm{H}_{9} \mathrm{ClF}_{4} \mathrm{NP} \mathrm{C}, 1788, \mathrm{H}, 450, \mathrm{~N}, 695, \mathrm{Cl}$, $1760 \%$ Found C, $1790, \mathrm{H}, 450, \mathrm{~N}, 690, \mathrm{Cl}$, $1759 \%$

\section{Spectroscopic Measurements}

${ }^{1} \mathrm{H}$ and ${ }^{19} \mathrm{~F}$ NMR measurements were made on Varian A60 and Varian A56/60 spectrometers, respectively NMR samples were prepared by dissolving $\mathrm{ClF}_{4} \mathrm{P} \cdot \mathrm{NMe}_{3}$ in $\mathrm{CD}_{3} \mathrm{CN}$ The NMR tubes were sealed off in vacuo with the sample held at $-196{ }^{\circ} \mathrm{C}$ It was found that the samples decomposed (with slight etching of the Pyrex glass) upon standing for two weeks at ambient temperature

\section{Results and Discussion}

The analytical data establish that the reaction of $\mathrm{PF}_{4} \mathrm{Cl}$ with $\mathrm{Me}_{3} \mathrm{~N}$ results in the formation of a 11 complex Assuming a locally octahedral geometry about the hexacoordinate phosphorus atom, two geometrical isomers are possible for this compound, trans (I) and cts (II)

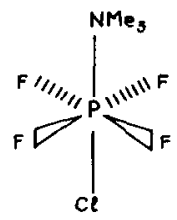

(1)

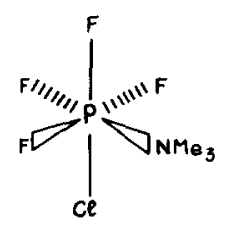

(II)
The fact that the ${ }^{19} \mathrm{~F}$ NMR spectrum of $\mathrm{ClF}_{4} \mathrm{P}$. $\mathrm{N}\left(\mathrm{CH}_{3}\right)_{3}$ exhibits only one type of resonance (Table I) clearly establishes the preference for the trans geometry, (l) The equivalence of the fluoride ligands is also apparent from the ${ }^{1} \mathrm{H}$ NMR spectrum which 
TABLE 1. Nuclear Magnetic Resonance Parameters for $\mathrm{ClF}_{4} \mathrm{P} \cdot \mathrm{NMe}_{3}$.

\begin{tabular}{llll}
\hline $\begin{array}{l}\text { Nuclcus observed } \\
\text { (splitting pattern) }\end{array}$ & $\mathbf{J}_{\mathrm{XY}}$ (IIz) & $\mathbf{J}_{\mathrm{XF}}$ (Ilz) & Shift (ppm) \\
\hline${ }^{1} \mathrm{H}$ (doublet of \\
$\begin{array}{c}\text { quintets) } \\
19\end{array}$ & 9.2 & 2.2 & $\delta=3.28$ \\
$\begin{array}{c}\mathrm{F} \text { (doublet of un- } \\
\text { resolved multiplets) }\end{array}$ & 970 & - & $\delta=31.7$ \\
\hline
\end{tabular}

${ }^{a}$ Relative to external $\mathrm{Me}_{4} \mathrm{Si}$ or $\mathrm{CCl}_{3} \mathrm{~F}$ for ${ }^{1} \mathrm{H}$, and ${ }^{19} \mathrm{~F}$ respectively (Upfield + , downfield - ).

consists of a doublet of quintets. In a previous study, Holmes and Gallagher [5] noted that the ${ }^{19} \mathrm{~F}$ NMR spectrum of the pyridine (py) complex of $\mathrm{PF}_{2} \mathrm{Cl}_{3}$ comprised 'only one doublet'. It can be implied therefore that the preferred geometry for this complex is (III) rather than (IV).<smiles>F[As](F)(F)(Cl)(Cl)Cl</smiles><smiles>F[As](F)(F)(Cl)(Cl)Cl</smiles>

Note that the preferred geometries, (I) and (III), both feature chloride ligands trans to the Lewis base, while the disfavored isomers, (II) and (IV) both have fluoride ligands trans to the Lewis base. This trans chloride preference may be a consequence of minimizing steric repulsions between the Lewis base and halide ligands. Alternatively, the observed isomeric preferences may result from the operation of subtle electronic effects.
The one-bond $\mathrm{P}-\mathrm{F}$ coupling constant, $\mathrm{J}_{\mathbf{P F}}$, in $\mathrm{ClF}_{4} \mathrm{P} \cdot \mathrm{N}\left(\mathrm{CH}_{3}\right)_{3}($ Table 1$)$ is smaller than that in the free phosphorane $(1000 \mathrm{~Hz})$ [5]. The same trend is apparent when $\mathrm{PF}_{5}$ coordinates to $\mathrm{Me}_{3} \mathrm{~N}$ [6], $\mathrm{Me}_{3} \mathrm{P}$ $[7]$, or $\mathrm{F}^{-}[8,9]$. Such a trend is anticipated on the basis of the Fermi contact term since in a free phosphorane, the average $\% \mathrm{P}(3 \mathrm{~s})$ character in the $\mathrm{dsp}^{3}$ hybrid orbitals is $\sim 20 \%$, while for octahedral hybrid orbitals the \%P (3s) character is $\sim 16.7 \%$. This generalization should be applied cautiously, however, because ${ }^{1} \mathrm{~J}_{\mathrm{PF}}$ is 996 and $1049 \mathrm{~Hz}$ in $\mathrm{PCl}_{4} \mathrm{~F}$ and $\mathrm{Cl}_{4} \mathrm{FP} \cdot \mathrm{NC}_{5} \mathrm{H}_{5}[5]$ respectively.

\section{Acknowledgments}

The authors are grateful to the National Science Foundation (Grant CHE-7910155) and the Robert A. Welch Foundation for generous financial support.

\section{References.}

1 R. Schmutzler, Adv. Fluorine Chem., 5, 31 (1965).

2 M. Webster, Chem. Rev., 66, 87 (1966).

3 R. H. Neilson and A. H. Cowley, Inorg. Chem., 14, 2019 (1975).

4 R. P. Carter, Jr., and R. R. Holmes, Inorg. Chem., 4, 738 (1965).

5 R. R. Holmes and W. P. Gallagher, Inorg. Chem., 2, 433 (1963).

6 F. N. Tebbe and E. L. Muetterties, Inorg. Chem., 6, 129 (1967).

7 C. W. Schultz and R. W. Rudolph, J. Am. Chem. Soc., 93, 1898 (1971).

8 G. S. Reddy and R. Schmutzler, Z. Naturforsch., 25b, 1199 (1970).

9 E. L. Muetterties, T. A. Bither, M. W. Farlow, and D. D. Coffman, J. Inorg. Nucl. Chem., 16, 52 (1960). 